\title{
A PROMOÇÃO DA INCLUSÃO DIGITAL DE PROFESSORES EM EXERCÍCIO: UMA PESQUISA DE SÍNTESE SOBRE APROXIMAÇÕES ENTRE PROFESSORES, NOVAS MÍDIAS E MANIFESTAÇÕES CULTURAIS EMERGENTES NA ESCOLA*
}

\author{
Gilberto Lacerda Santos \\ Universidade de Brasília, Brasília, Distrito Federal, Brasil
}

\begin{abstract}
Resumo: O artigo apresenta os resultados der uma Pesquisa de Síntese centrada na identificação de fatores suscetíveis de impulsionar a inclusão digital de professores em serviço. Quatro dissertações de mestrado, realizadas entre os anos de 2011 e 2013, deram forma à investigação metanalítica e seus resultados são aqui apresentados, discutidos e contextualizados. As conclusões gerais apontam que determinados fatores de promoção da inclusão digital de professores em exercício (imersão e alfabetização computacional) devem ser priorizados em detrimento de outros (mobilização e instrumentação). $\mathrm{O}$ artigo sinaliza para a complexidade da formação continuada de professores, especialmente quando se trata da construção e do desenvolvimento de competências, habilidades e atitudes com relação às novas mídias e às manifestações culturais emergentes na escola.

PALAVRAS-CHAVE: Cultura digital. Formação continuada de professores. Inclusão digital.
\end{abstract}

A CONTUNDENTE PROBLEMÁTICA DA INCLUSÃO DIGITAL DE PROFESSORES EM EXERCÍCIO

Promover a inclusão digital de professores em exercício e inseri-los nos novos contextos culturais, decorrentes das tecnologias digitais, têm sido

\footnotetext{
* Artigo recebido em 7/3/2014 e aprovado em 5/5/2014.
} 
um desafio hercúleo, enfrentado há várias décadas pelas diversas instâncias do poder público brasileiro, sem que tenhamos, a nosso ver, efetivamente avançado na questão. Isso porque a promoção da inclusão digital do professor consiste em um processo substantivamente distinto daquele que se refere à inclusão digital de modo geral.

O professor, colocado na situação de "conectado", deve compreender o papel e o potencial pedagógico das Tecnologias Digitais de Informação, Comunicação e Expressão (TDICE), assim definidas justamente por serem suportes privilegiados e inovadores para que nos informemos com mais intensidade, para que nos comuniquemos com mais agilidade e para que nos expressemos com mais liberdade. No contexto de uma rede social como a escola, os impactos são contundentes. O professor deve, portanto, percebê-las e assimilá-las como meios didáticos poderosos para a dinamização de suas ações educativas, para o estabelecimento de conexões com o cotidiano dos alunos, para acirrar a pertinência da escola no contexto de uma sociedade cada vez mais digital, cada vez mais centrada na exploração dessas tecnologias em todos os setores da ação humana e, por fim, para promover aproximações entre eles próprios e as manifestações culturais emergentes no ambiente escolar, decorrentes da exploração dessas tecnologias, tão presentes na vida cotidiana de seus alunos e também dos próprios professores, os quais, por força de diversas circunstâncias, têm se tornado cidadãos de dois mundos: o mundo conectado, fora da escola, e o mundo da comunicação linear, dentro da escola.

Ora, se prover formação inicial para desenvolver esse perfil nos futuros professores continua sendo uma meta longínqua para a sociedade brasileira, posto que, em pleno século XXI, a maioria dos cursos de formação de professores (Pedagogias e Licenciaturas) sequer oferece disciplinas relacionadas com as tecnologias educativas, impulsionar o desenvolvimento desse perfil e das competências e habilidades a ele relacionadas junto a professores em exercício, muitos deles formados há 10, 20 anos, é um verdadeiro imbróglio.

Diante dessa problemática, a Pesquisa de Síntese cujos resultados são apresentados neste artigo, teve como foco a identificação de fatores suscetíveis de impulsionar a atuação de professores em exercício, no que se refere ao uso pedagógico das novas mídias e à imersão no universo da cultura digital decorrente das possibilidades de informação, comunicação e expressão trazidas pelas TDICE: Seriam ações de mobilização desses professores para fazê-los vivenciar situações didáticas mediadas por essas tecnologias digitais? Seriam ações de imersão em situações de exploração específica das TDICE 
para que os docentes passem a perceber-se como atores centrais do processo de sua própria inclusão digital? Seria a instrumentalização dos professores, por meio da disponibilização de materiais didáticos ergonomicamente concebidos para facilitar a mediação pedagógica com o uso de TDICE? Seria continuar insistindo em ações tradicionais de alfabetização computacional, por meio de programas de inclusão digital, da mesma forma como isto vem sendo empreendido?

Assim, à luz dessas quatro questões de pesquisa, quatro dissertações de mestrado acadêmico foram desenvolvidas nos anos de 2011 a 2013, no âmbito das atividades do Laboratório Ábaco de Pesquisas interdisciplinares sobre Tecnologias e Educação, na Faculdade de Educação da Universidade de Brasília. A investigação conduzida por Kempfer (2012) teve como contexto geral a verificação do potencial de ações de mobilização de professores, em serviço, com a finalidade de sensibilizá-los para o uso pedagogicamente apropriado das TDICE. Nesse contexto, a pesquisadora buscou identificar, em escolas públicas municipais do ensino fundamental da cidade de Goiânia (GO), situações nas quais tais ações de mobilização docente acontecem, a fim de analisar os impactos da cultura digital na mediação pedagógica.

Por sua vez, a investigação conduzida por Falcão (2012) buscou verificar se ações de imersão em situações de exploração específica das TDICE ajudam o professor a perceber-se como ator central do processo de promoção de sua própria inclusão digital. Mais especificamente, utilizando o projeto UCA (Um Computador por Aluno) como pano de fundo, a pesquisadora investigou os modos de interação construídos e praticados por professores e alunos atuantes no referido projeto, em escolas do Distrito Federal.

Paralelamente, a investigação conduzida por Silva (2013) foi vinculada à terceira questão delimitadora da Pesquisa de Síntese e procurou verificar se a instrumentalização dos professores, por meio da disponibilização de materiais didáticos ergonomicamente concebidos para facilitar a mediação pedagógica com o uso de TDICE, pode facilitar as relações entre professores e essas tecnologias, aproximando-os do contexto cultural por elas determinado. Nesse âmbito geral, o investigador analisou as relações entre a usabilidade e o processo de mediação pedagógica em uma situação de educação a distância, na Universidade Aberta do Brasil.

Por fim, a quarta investigação, conduzida por Firmino (2012), relacionou-se com a avaliação de ações tradicionais de alfabetização computacional, por meio de programas de inclusão digital, da mesma forma como isso vem sendo promovido por determinadas políticas públicas, e de sua eficácia na promoção de aproximações entre professores em exercício e as TDICE. Mais 
especificamente, o investigador debruçou-se sobre o modo de funcionamento do Curso de Especialização em Gestão Escolar do Programa Nacional Escola de Gestores do Ministério da Educação, oferecido como meio de formação continuada a professores do Distrito Federal e cidades do seu entorno, a fim de verificar o que lunes e Lacerda Santos (2013) chamaram de contratos e destratos entre professores e TDICE.

Assim sendo, a Pesquisa de Síntese relatada neste artigo levou em consideração as problemáticas e as conclusões dos quatro mestrandos, não vistas isoladamente, mas interconectados por uma intenção investigativa que perpassou cada uma das investigações citadas: ampliar o estado da arte sobre a questão da inclusão digital do professor em serviço e compreender meandros da aproximação de docentes, no exercício da profissão, com as novas mídias e com a cultura digital por elas instituída.

MetOdologia de INVESTIGAÇÃO: A PESQUISA DE SÍNTESE

A Pesquisa de Síntese (LACERDA SANTOS, 2006), cuja estrutura epistemológica foi elaborada a partir da proposta da Pesquisa Metanalítica proposta por Petitte (1994), consiste em um empreendimento investigativo edificado em torno de procedimentos de consideração de resultados de pesquisas individuais, integradas em torno de objetivos gerais mais amplos, dos quais decorrem objetivos específicos tratados em cada pesquisa. Em quatro outras oportunidades, empregamos a Pesquisa de Síntese para subsidiar iniciativas de metanálise.

Primeiramente, em Lacerda Santos (2006), seis investigações de mestrado, conduzidas ao longo de 7 anos consecutivos, permitiram a identificação de elementos suscetíveis de contribuírem para a elucidação da problemática de se formar professores para a educação mediada por tecnologias. Nessa oportunidade, a Pesquisa de Síntese, como estratégia metanalítica de um conjunto de investigações integradas, foi proposta pela primeira vez à comunidade de pesquisadores em educação por meio de uma mesa redonda no XIII Encontro Nacional de Didática e Prática de Ensino, realizado na Universidade Federal de Pernambuco. Em seguida, em Lacerda Santos, Ferreira e Castro (2009), a Pesquisa de Síntese foi novamente colocada em perspectiva, em um artigo científico no qual foram apresentados os resultados de uma investigação metanalítica longitudinal sobre o potencial da Pedagogia de Projetos na promoção da inclusão digital de professores. A investigação foi realizada durante quatro anos, por meio de duas dissertações de mestrado, conduzidas por dois professores da rede pública de ensino do Distrito Federal. 
Igualmente, em Lacerda Santos (2011a), a Pesquisa de Síntese foi mais uma vez apresentada à comunidade científica, em um periódico de alcance internacional, como metodologia empregada para nortear uma investigação sobre o fenômeno da migração da sala de aula convencional para a sala de aula virtual. Essa investigação procurou configurar a crise paradigmática em torno da ruptura entre a sala de aula presencial e a sala de aula virtual, tendo em vista a emergência da sociedade da informação, por meio de dados empíricos coletados em 13 dissertações de mestrado integradas, na forma de uma pesquisa longitudinal, realizada entre $2004 \mathrm{e}$ 2008, financiada pelo Conselho Nacional de Desenvolvimento Científico e Tecnológico (CNPq), pela Fundação de Apoio à Pesquisa do Distrito Federal (FAPDF) e pela Fundação Nacional de Desenvolvimento do Ensino Superior Privado (Fenadesp). Os resultados dessa Pesquisa de Síntese foram também publicados em Lacerda Santos e Andrade (2010). Por fim, a abordagem da Pesquisa de Síntese foi empregada para "costurar" resultados de um conjunto de investigações individuais associadas, empreendidas em torno de um projeto de pesquisa e desenvolvimento, visando a concepção e o teste de uma plataforma educacional para o Departamento Nacional de Trânsito (LACERDA SANTOS, 2011b).

Nessas quatro investigações, a abordagem da Pesquisa de Síntese colocou-se a serviço da integração, em um fio condutor mais amplo, de uma série de investigações individuais e autônomas, alinhadas em torno de um objetivo geral que as permeava, mesmo não sendo claramente identificado e declarado em cada pesquisa considerada em particular. Enquanto abordagem metanalítica, a Pesquisa de Síntese permite a um líder de um grupo de pesquisas, ou a um pesquisador-orientador, associar diversas pesquisas ou diversos pesquisadores-orientandos em torno de uma mesma investigação, levando-os a contribuírem, de forma explícita ou implicitamente colaborativa, para a construção de elementos de resposta para o problema considerado.

Como já ressaltamos em outras apresentações da abordagem, é evidente que, considerando o papel dos atores envolvidos no procedimento (orientador e orientandos; pesquisador-líder e pesquisadores-liderados), a abordagem metanalítica adquire contornos de pesquisa participante, definida por Haguette (1985) como um processo concomitante de geração de conhecimento entre todos os participantes; um processo educativo, que busca a intertransmissão (sic) e o compartilhamento dos conhecimentos; e um processo de mudança, seja aquela que ocorre durante a pesquisa, isto é, a mudança imediata, seja aquela projetiva, que extrapola o âmbito e a temporalidade da pesquisa, na busca de transformações estruturais práticas que favoreçam os atores envolvidos na investigação. 
A Pesquisa de Síntese, enquanto estratégia metanalítica, serve-se de uma espécie de metametodologia, a qual integra não apenas os objetos de pesquisa individuais de cada investigação integrada mas também as diferentes abordagens metodológicas empregadas por cada pesquisador implicado no empreendimento investigativo. Assim, a metodologia de coleta e análise de dados, por meio da qual a Pesquisa de Síntese se consolida e se realiza, é o somatório das metodologias de coleta e análise de dados das investigações que a constituem. Nessa perspectiva, compete ao pesquisador-líder ou ao pesquisador-orientador, na condição de condutor da Pesquisa de Síntese, zelar pela coerência teórica e metodológica das pesquisas por ele conduzidas e que lhe permitirão, em uma etapa posterior, fazer fechamentos conceituais, analisar e integrar os resultados das diferentes investigações e elaborar as metaconclusões que ele busca. No caso da pesquisa metanalítica aqui descrita, o trabalho de síntese perpassou quatro problemas de pesquisa e quatro procedimentos metodológicos distintos, descritos em cada dissertação de mestrado integrada, todos girando em torno do mesmo metaobjetivo, ou seja, identificar fatores suscetíveis de impulsionar a atuação de professores, em exercício, no que se refere ao uso pedagógico das novas mídias e à sua imersão no universo da cultura digital decorrente das possibilidades de informação, comunicação e expressão trazidas pelas TDICE.

\section{DESENVOLVIMENTO DA INVESTIGAÇÃO METANALÍTICA}

Um projeto integrado de pesquisas, para fazer jus à terminologia empregada pelo CNPq, é um projeto articulado, que se desdobra em subprojetos que são desenvolvidos em parceria com outros pesquisadores, com profissionais de outras instituições ou com estudantes em formação. Já os subprojetos, ou projetos pontuais ou desdobrados, devem esclarecer a relação direta que possuem com o projeto integrador, ou seja, precisam estabelecer conexões, implícita ou explicitamente declaradas, com o projeto maior do ponto de vista teórico, metodológico e/ou de campo. As quatro dissertações de mestrado, integradas em torno do projeto ora apresentado, tiveram vários pontos de convergência, todos conectados com a intenção de se compreender relações entre professores em exercício e TDICE, na perspectiva da promoção de sua inclusão digital. A problematização desse tema foi elaborada, concomitantemente, por todos os quatro pesquisadores, em direções distintas, mas totalmente complementares.

A análise feita por Kempfer (2012) desse cenário da integração pedagógica das TDICE a fez observar que qualquer mudança na escola exige tempo e esforço, tendo em vista o próprio modo de funcionamento 
dessa instituição secular e a forma como seus atores a concebem. Para a pesquisadora, nós somos testemunhas de um processo de formulação de uma nova cultura, a Cibercultura, o que supõe a substituição de muitas crenças e valores que até então orientaram a ação pedagógica por outras mais condizentes com o momento histórico vivido. Todavia, ela observa que, além de formular uma nova cultura, a escola deve mudar sua própria estrutura, bem como sua percepção sobre o aprender e suas estratégias para ensinar. Bastante imbuída do pensamento de Levy (1999) e de Pretto (2008), a pesquisadora desenvolve toda uma argumentação sobre a necessidade de se qualificar o acesso de professores a tecnologias, para fins educativos. Para ela, o acesso às tecnologias materiais, isto é, aos computadores e tablets, deve necessariamente ser acompanhado de políticas públicas que garantam a compreensão desse aparato tecnológico e um posicionamento crítico com relação a ele, para se evitar usos passivos e que não agregam valor às relações educativas, tendo em vista que:

Nessa perspectiva de saber agir pedagogicamente com as tecnologias educacionais, o professor coloca o aluno numa condição ativa que permite a interação (material e inteligente) com as mídias. Nesse processo de ensino e aprendizagem, o papel do professor é fundamental na mediação pedagógica, porque a escola é por excelência o lugar de ensino. Portanto, trabalhar com as novas tecnologias implica em trabalhar com novas pedagogias. Nesse contexto, a apropriação da cultura digital passa a ser de suma importância na reorganização das relações educativas (KEMPFER, 2012, p. 50)

Por sua vez, e de forma totalmente complementar às ideias de Kempfer (2012), Falcão (2012), buscando subsídios teóricos em Masetto (2000) e em Kenski (1998), articula a ideia de que o uso das tecnologias digitais pode contribuir para uma nova práxis, em um novo fazer pedagógico que poderá se transformar e se reestruturar em um novo conceito de aprender e em uma nova forma de ensinar, constituindo um ambiente propício às aprendizagens. Evidentemente, a pesquisadora adverte em seu trabalho que isso não acontece de forma automática, mas à custa de investimentos pessoais, por parte dos professores, relacionados com a apreensão do saber fazer pedagógico com a mediação tecnológica. Portanto, procedimentos de promoção da inclusão digital do professor devem vislumbrar sua capacitação profissional para atuar em tal cenário no qual interações estáticas dão lugar a interações dinâmicas, termos que Falcão (2012) emprestou do campo da Física para categorizar dois modos opostos de relações entre professores e TDICE e que a colocam no mesmo diapasão que Kempfer (2012). Para a pesquisadora, a experiência de professores com essas tecnologias 
...é um desafio importante para as escolas, visto que pode propiciar renovações pedagógicas e novos saberes, novas formas de linguagem, novas leituras e produções de conhecimento que evocam criatividade e senso crítico. Não é o aparato técnico que fará a diferença, mas o modo de condução do professor ao explorar as inúmeras potencialidades destes recursos capazes de transformar a própria ação educativa. (FALCÃO, 2012, p. 20)

Enquanto os trabalhos de Kempfer (2012) e Falcão (2012) se detiveram sobre professores em situações de educação presencial (a primeira abordou professores de escolas da cidade de Goiânia, equipadas com laboratórios de informática, e a segunda, professores de escolas do Distrito Federal, participantes do projeto UCA), os trabalhos de Firmino (2012) e Silva (2013) se detiveram sobre professores em situações de educação a distância. Entretanto, os quadros conceituais e os argumentos desenvolvidos pelos pesquisadores agregaram novos elementos ao mesmo esforço de problematização que nos mobilizava a todos: a questão da inclusão digital de professores em exercício.

Dentre os diversos argumentos desenvolvidos por Firmino (2012), ganha ênfase aquele que menciona que os professores não têm conseguido avançar em sua própria fluência no meio digital, tendo em vista que projetos oficiais de inclusão digital de professores não são bem-sucedidos devido à ausência, total ou parcial, de elementos que permitam aos educadores avançarem em abordagens qualitativamente efetivas da informática e de suas possibilidades informacionais, comunicacionais e expressivas. Temos aí um clamor pelo mesmo avanço do estático para o dinâmico, proposto por Falcão (2012), e pelo abandono da passividade, proposto por Kepfer (2012). O pesquisador aponta, sem dubiedades, o problema delimitado pela crença, subjacente a diversas políticas públicas, de que a inclusão digital do professor é atingível pela simples possibilidade de seu acesso a computadores e outros aparatos de conexão à internet. Todavia, conforme mencionado no início deste texto e corroborado pelo próprio Firmino (2012), a inclusão digital do professor é de natureza didática e operacional. Deve ter como foco não apenas habilidades e competências de navegação na internet, de forma passiva, mas sua apropriação como instrumento de ensino e como meio de aprendizagem, isto é, como instrumento de trabalho. Aí, são outros quinhentos, como nos sugere Firmino (2012), que enfatiza também a persistência da insegurança dos professores com relação às tecnologias na escola:

Existe [ainda] certo temor, por parte dos professores, de que a tecnologia venha a substituí-los como fonte principal de informação para seus alunos. Esta crise de identidade e de função é caracterizada por Silva (2010) como uma "crise de autoridade". Deste modo, tudo aquilo que não vier das fontes 
oficiais, dos livros didáticos e de fontes indicadas pelo professor, deve ser tomado com desconfiança e caracterizado como "indisciplina". (FIRMINO, 2012, p. 19)

Enquanto o olhar de Firmino (2012) foi lançado sobre ações tradicionais de alfabetização computacional, por meio de políticas públicas de promoção da inclusão digital de professores em serviço, o olhar de Silva (2013) foi direcionado para a instrumentalização dos professores, por meio da disponibilização de materiais didáticos ergonomicamente concebidos para facilitar a mediação pedagógica com o uso de TDICE, como promotores desse mesmo tipo de inclusão. Em sua abordagem da problemática, Silva (2013) propõe que o professor mediador, isto é, aquele devidamente mestre das tecnologias digitais e detentor de conhecimentos, habilidades e atitudes adequados para empregá-las em sua prática pedagógica, procurará fazer com que o aprendiz use e comande as TDICE em provimento de suas aprendizagens, em vez de ser comandado por elas em detrimento de seus processos cognitivos. Inspirado por Masetto (2000), o pesquisador argumenta que, com o advento das TDICE, é imperioso derrotar a visão transmissiva, segundo a qual o professor valoriza somente os conteúdos, privilegia a aula expositiva e avalia por meio da conferência da assimilação das informações por ele transmitidas, cabendo ao aluno permanecer numa atitude passiva, o que, na verdade, implica também em uma grande passividade por parte do professor. Sobretudo, ele enfatiza que:

...um professor que assume uma postura transmissiva/tradicional terá dificuldades em utilizar as tecnologias no fazer pedagógico de uma maneira que busque desenvolver essas novas competências, habilidades e atitudes requeridas atualmente. Para que o uso de tecnologias no processo de mediação pedagógica possa criar alguma inovação, o professor deve sair do papel de transmissor e passar a atuar como um mediador. (SILVA, 2013, p. 41)

Explicitados seus respectivos posicionamentos teóricos, os quatro pesquisadores avançaram em suas investigações, empregando métodos, metodologias e instrumentos de coleta de dados igualmente convergentes. Kempfer (2012), para abordar professores goianenses, de escolas com laboratórios de informática, a fim de verificar se e como a cultura digital vem sendo integrada por eles ao seu trabalho pedagógico, serviu-se de observações e entrevistas semiestruturadas com enfoque qualitativo. Já Falcão (2012), para abordar os modos de interação construídos e praticados por professores e alunos atuantes no projeto UCA, em escolas do Distrito Federal, realizou observações de aulas e entrevistas com esses atores, sempre em uma 
perspectiva de abordagem qualitativa. Firmino (2012), a seu turno, com o objetivo de propor uma redefinição do conceito de inclusão digital implícito nas políticas públicas de formação continuada de professores mediada pelas TDICE, e situando-se na mesma vertente epistemológica, realizou um estudo de caso no contexto do qual coletou dados por meio de questionários digitais. Finalmente, Silva (2013), com o objetivo de analisar o diálogo entre a usabilidade do material didático digital e o processo de mediação pedagógica, recorreu a um estudo qualitativo de natureza descritiva, para o qual coletou dados por meio de entrevistas semiestruturadas.

Esse corpo metodológico, que deriva de cada pesquisa integrada, dá forma e sustentação à pesquisa metanalítica e permitiu a obtenção dos resultados que serão discutidos, de forma igualmente integrada, na seção a seguir.

\section{ANÁLISE DAS CONCLUSÕES DAS PESQUISAS INTEGRADAS}

No âmbito de uma Pesquisa de Síntese, analisar conclusões das pesquisas que a delimitam, bem como buscar conclusões que tenham sentido de forma ampla, implica em se fixar nos fios condutores comuns das investigações, os quais, no caso aqui apresentado, têm como foco a identificação de fatores suscetíveis de impulsionar a atuação de professores, em exercício, no que se refere ao uso pedagógico das novas mídias e à imersão no universo da cultura digital decorrente das possibilidades de informação, comunicação e expressão trazidas pelas TDICE. Nesse sentido, as investigações de Kempfer (2012), Falcão (2012), Firmino (2012) e Silva (2013) são clarividentes e alardeiam que, sem formação inicial adequada, a demanda por formação continuada de professores para um uso efetivo e eficaz das TDICE é homérica e as soluções que têm sido empregadas não têm, de modo geral, surtido efeito.

Os dados coletados e analisados pelos quatro pesquisadores revelam uma situação preocupante, que nos remete à necessidade de intervenções urgentes nos mecanismos de formação inicial de professores, sob pena de perpetuarmos a situação ora vigente, em que docentes em exercício, mesmo os recém-formados, não dispõem do aparato conceitual e empírico necessário para lidar com as TDICE, o que, paradoxalmente, é uma das metas do governo brasileiro. O resultado da investigação de Kempfer (2012) demonstra que a integração da cultura digital na mediação pedagógica depende mais do trinômio formação-engajamento-motivação do que do provimento de equipamentos e de disponibilização de infraestrutura. Já os resultados da investigação conduzida por Falcão (2012) anunciam que o professor é o principal elemento na condução de uma ação educativa eficaz no que diz respeito à promoção da interatividade, encontrada a 
partir de uma interação dinâmica com as TDICE. Consequentemente, se ele não dispõe de um arsenal didático adequado para empregar na gestão de situações educativas mediadas por tais tecnologias, essas últimas tendem a ser estáticas e desmotivadoras e desengajantes, tanto para os alunos quanto para eles mesmos, os professores. A investigação de Firmino (2012) nos leva à conclusão de que toda e qualquer iniciativa de inclusão digital de professores deve estar ancorada na apropriação de novos conhecimentos, habilidades e atitudes, específicos para o manejo efetivo das TDICE, e não em equipamentos ou no mero acesso à internet. Eis a razão, conclui o pesquisador, que explica a ineficácia de grande parte das políticas públicas diretamente voltadas para a promoção da inclusão digital de professores ou aquelas que se servem de uma pretensa inclusão digital desses profissionais para se alcançar outros objetivos em termos de sua formação continuada.

Quanto a Silva (2013), ele traz sua voz para esse coro ao apontar que, nem mesmo materiais didáticos digitais, concebidos segundo princípios de ergonomia e usabilidade próprios da nova cultura digital, são suficientes para mobilizar professores sem formação inicial adequada, os quais permanecem carecendo de uma formação específica para apropriar, compreender e empregar tais materiais didáticos e, consequentemente, para conduzir adequadamente relações educativas por eles mediadas.

Tais conclusões apontam para o papel central do professor na condução de relações educativas mediadas pelas TDICE e para a urgência de uma verdadeira mobilização em torno da promoção de sua inclusão digital, desde a formação inicial, nos cursos de Pedagogia e nas Licenciaturas. Sem essa premissa resolvida, sem que essa situação problemática seja ultrapassada, continuaremos, por muito tempo ainda, a prover nossas redes de ensino com profissionais didaticamente ultrapassados, com atuações incoerentes com relação ao que se passa fora da escola e com relação à cultura cotidiana de seus alunos. Isso posto, passemos às conclusões da Pesquisa de Síntese que agregou as quatro investigações de mestrado aqui apresentadas.

\section{CONCLUSÕES}

Enquanto projeto integrado de pesquisa, nosso objetivo mais amplo foi o de identificar fatores suscetíveis de impulsionar a atuação de professores, em exercício, no que se refere ao uso pedagógico das novas mídias e à imersão no universo da cultura digital decorrente das possibilidades de informação, comunicação e expressão trazidas pelas tecnologias digitais. Para que atingíssemos esse objetivo geral, quatro questões específicas foram formuladas e articuladas em quatro dissertações de mestrado distintas e 
complementares. A primeira questão procurava saber se ações de mobilização desses professores para fazê-los vivenciar situações didáticas mediadas por essas tecnologias digitais seriam suficientes para impulsionar ou promover sua inclusão digital. E a resposta é negativa. O fator "mobilização", identificado a partir da investigação de Kempfer (2012), não se revelou suficiente porque, apesar de gerar expectativas positivas e "simpatias" com relação às TDICE e ao seu potencial pedagógico, não é suficiente para promover uma inclusão digital de professores, tal como definida anteriormente, nesse mesmo texto. Apesar de encontrarmos casos pontuais que indicam essa possibilidade, de modo geral, falta aos professores o lastro da formação inicial para que usufruam, de fato, de toda e qualquer ação de mobilização em torno da exploração pedagógicas das TDICE.

A segunda questão procurou saber se a imersão do professor em ações pontuais de exploração específica das TDICE auxiliariam os docentes a perceber-se como atores centrais do processo de promoção da interatividade no ambiente da escola e, consequentemente, impulsionaria sua inclusão digital. Nesse caso, foi possível vislumbrar possibilidades concretas de promoção da inclusão digital dos professores em serviço. Todavia, o investimento no fator "imersão", identificado a partir da investigação de Falcão (2012), sempre é demasiado grande, dado o universo educacional brasileiro, e as dificuldades de universalização, isto é, de sua extensão a um grande número de professores, o que sempre é bastante oneroso e exige mobilizações de grande porte.

A terceira questão procurou saber se a instrumentalização dos professores, por meio da disponibilização de materiais didáticos ergonomicamente concebidos, poderia facilitar a mediação pedagógica com o uso de TDICE e, consequentemente, promover sua inclusão digital. O fator "instrumentalização", identificado a partir da investigação de Silva (2013), mostrou-se tão mobilizador quando o fator anterior (imersão). Todavia, ficou evidente que, mesmo materiais didáticos indutores de determinados habilidades e atitudes por parte dos professores, ainda dependem fortemente do conhecimento detido por esses últimos sobre as TDICE e seu potencial pedagógico, o que adviria de uma formação inicial que tivesse algum foco na construção de tais conhecimentos.

Finalmente, a quarta e última questão buscava saber se continuar insistindo em ações de tradicionais de alfabetização computacional, por meio de programas de inclusão digital, da mesma forma como isto vem sendo empreendido, poderia, a médio e longo prazo, dar resultados efetivos e impulsionar a inclusão digital dos professores. Nesse caso, a resposta é negativa, posto que o fator "alfabetização computacional", identificado a 
partir da investigação de Firmino (2012), desenvolvido seja em contextos de formação inicial, seja em contextos de formação continuada muito específicos, é variável dependente do próprio sucesso de iniciativas de formação continuada com e sobre as TDICE.

Assim sendo, dos quatro fatores identificados, dois se mostraram insuficientes (mobilização e alfabetização computacional) e dois se mostraram promissores (imersão e instrumentalização) para a promoção da inclusão digital de professores em serviço, o que nos leva a concluir que a aproximação de professores, no exercício da profissão, com as novas mídias e com as manifestações culturais emergentes na escola, é dependente de situações de contato intensivo e específico (em termos didáticos) com as TDICE. Por exemplo, a promoção de experiências concretas de manipulação de dispositivos digitais e de objetos de aprendizagem concebidos à luz das novas pedagogias reivindicadas por Pretto e Pinto (2006).

Evidentemente, não concluímos aqui uma investigação exaustiva, que encerra a questão, a qual é bastante complexa. O Brasil tem um dos maiores contingentes de professores em exercício do mundo, grande parte formada de acordo com premissas didáticas anteriores àquelas que foram elaboradas a partir da emergência das tecnologias digitais e de sua inserção no ambiente escolar. Fazê-los migrar da"sala de aula convencional" para a"sala de aula virtual" tem se mostrado praticamente impossível. Por outro lado, as Faculdades de Educação e os cursos de Licenciatura contam com formadores de professores, de modo geral, igualmente distanciados do uso pedagógico das TDICE, o que nos leva a vislumbrar uma continuação do cenário atual, por ainda um bom tempo. A mudança almejada situa os ambientes de formação de professores no olho do furacão e sem sua reestruturação didática e epistemológica, todos os esforços de inclusão digital de professores em serviço tendem a apresentar resultados insuficientes.

PROMOTING THE DIGITAL INCLUSION OF IN-SERVICE TEACHERS: A RESEARCH SYNTHESIS ON BONDS BETWEEN TEACHERS, NEW MEDIA AND EMERGING CULTURAL EVENTS IN THE SCHOOL

AвSTRACT: The article presents the results of a Research Synthesis which focused on identifying those factors most likely to boost the digital inclusion of in-service teachers. Four Master theses, carried out between 2011 and 2013, were the basis for the meta-analytic research. Their results are presented, discussed and contextualised. The general findings suggest that certain factors which promote the digital inclusion of in-service teachers (immersion and computer literacy) should be prioritized over others (mobilization and instrumentation). The paper points to the complexity of the on-going formation of teachers, especially when it comes to the construction and 
development of skills, abilities and attitudes towards the new media and emerging cultures in the school.

KEY WORDS: Digital culture. On-going teacher formation. Digital inclusion.

LA PROMOCIÓN DE LA INCLUSIÓN DIGITAL DE LOS DOCENTES EN EJERCICIO: UNA INVESTIGACIÓN DE SÍNTESIS SOBRE LAS APROXIMACIONES ENTRE PROFESORES, NUEVOS MEDIOS Y MANIFESTACIONES CULTURALES EMERGENTES EN LA ESCUELA

RESUMEN: El artículo presenta los resultados de una investigación de síntesis centrada en la identificación de los factores que pueden promover la inclusión digital de docentes en ejercicio. Cuatro disertaciones de maestría, llevadas a cabo entre los años 2011 y 2013, compusieron la investigación meta-analítica y sus resultados son aquí presentados, debatidos y contextualizados. Las conclusiones generales sugieren que ciertos factores de promoción de la inclusión digital de los docentes en ejercicio (inmersión y alfabetización informática) deben tener prioridad sobre otros (movilización y instrumentación). El documento apunta a la complejidad de la formación continuada de los maestros, sobre todo cuando se trata de la construcción y del desarrollo de las competencias, habilidades y actitudes hacia los nuevos medios y las manifiestaciones culturales emergentes en la escuela.

Palabras Claves: Cultura digital. Formación continuada de profesores. Inclusión digital.

\section{REFERÊNCIAS}

FALCÃO, A. B. F. Interações entre professores e alunos em situações de ensino- aprendizagem mediadas por NTICE: retratos do projeto UCA no Distrito Federal (DF). Dissertação (Mestrado em Educação) - Faculdade de Educação, Universidade de Brasília, Brasília, 2012.

FIRMINO, E. A. P. A inclusão digital de professores da Educação Básica Pública: o caso do Curso de Especialização em Gestão Escolar do Programa Nacional Escola de Gestores do Ministério da Educação. Dissertação (Mestrado em Educação) - Faculdade de Educação, Universidade de Brasília, Brasília, 2012.

HAGUETTE, T. M. F. Metodologias qualitativas na sociologia. Petrópolis: Vozes, 1985.

IUNES, S.; LACERDA SANTOS, G. Contratos e destratos entre Informática e Educação Matemática. Ciência e Educação, v. 19, n. 2, p. 293-305, Bauru, 2013.

KENSKI, V. Novas tecnologias: o redimensionamento do espaço e do tempo e os impactos no trabalho docente. Revista Brasileira de Educação, n. 8, Brasília, p. 58-71, maio/ago. 1998. 
KEMPFER, L. M. A. Impactos da Cibercultura na mediação pedagógica nas escolas públicas municipais do ensino fundamental da cidade de Goiânia (GO). Dissertação (Mestrado em Educação) - Faculdade de Educação, Universidade de Brasília, Brasília, 2012.

LACERDA SANTOS, G. Formar professores para a educação mediada por tecnologias: elucidação da problemática por meio de seis pesquisas acadêmicas. In: XIII Encontro Nacional de Didática e Prática de Ensino, 2006, Recife (PE). Anais do XIII ENDIPE, v. 1. p. 1-1. Recife (PE): Universidade Federal de Pernambuco, 2006.

. Ensinar e aprender no meio virtual: rompendo paradigmas. Educação e Pesquisa, v. 37, n. 2, p. 307-320, São Paulo, 2011 a.

. (Org.). Plataforma educacional do Denatran: relatos de um processo de pesquisa e desenvolvimento. Brasília: Liber Livros, $2011 \mathrm{~b}$.

; ANDRADE, J. Virtualizando a escola: migrações docentes rumo à sala de aula virtual. Brasília: Líber Livro, 2010.

; FERREIRA, M.; CASTRO, W. de. A pedagogia de projetos como estratégia de inclusão digital de professores. Educação e Cidadania, v. 1, n. 11, p. 31-54. Porto Alegre, 2009.

LÉVY, P. Cibercultura. Tradução de Carlos Irineu da Costa. São Paulo: Editora 34, 1999.

MASETTO, M. T. Mediação pedagógica e o uso da tecnologia. In: MORAM, J. M.; MASETTO, M. T.; BEHRENS, M. A. Novas tecnologias e mediação pedagógica. Campinas: Papirus, 2000.

PETITTI, D. Overview of methods. In: Meta-analysis, decision analysis and cost-effectiveness analysis in medicine. New York: Oxford University Press, 1994. p. 15-34.

PRETTO, N. de L. Cultura digital e educação: redes já! In: PRETTO, N. de L.; SILVEIRA, S. A. (Orgs.). Além das redes de colaboração: internet, diversidade cultural e tecnologias do poder. Salvador: EDUFBA, 2008. p. 75-83.

;PINTO, C. de C. Tecnologias e novas educações. Revista Brasileira de Educação, v. 11, n. 31, p. 19-30, jan./abr. 2006.

SILVA, G. A. da S. e. Análise da usabilidade no processo de mediação pedagógica em educação a distância a partir da percepção da professora. Dissertação (Mestrado em Educação) - Faculdade de Educação, Universidade de Brasília, Brasília, 2013.

SILVA, R. L. da. O direito à educação na sociedade informacional: desafios postos à Escola em face das novas tecnologias. Anais do XIX Encontro Nacional do CONPEDI Conselho Nacional de Pesquisa e Pós-Graduação em Direito, 2010.

Gilberto Lacerda Santos é professor associado do Departamento de Métodos e Técnicas da Faculdade de Educação da Universidade de Brasília.

E-mail: slacerda@unb.br 